\title{
Evaluation of the Prehospital Index, presence of high- velocity impact and judgment of emergency medical technicians as criteria for trauma triage
}

\author{
Andre Lavoie, $\mathrm{PhD} ;{ }^{*}{ }^{*}$ Marcel Émond, MD, MSc; ${ }^{* \ddagger}$ Lynne Moore, $\mathrm{PhD} ;{ }^{*}{ }^{*}$ Stéphanie Camden, $\mathrm{MSc} ;{ }^{\S}$ \\ Moishe Liberman, MD, PhD
}

\section{ABSTRACT}

Objective: We sought to evaluate the performance of the Prehospital Index (PHI), the high-velocity impact (HVI) criterion and emergency medical technician (EMT) judgment for the prehospital triage of injured patients.

Methods: The study population included all prehospital trauma patients transported by an emergency medical service to 2 level-I trauma centres for adults. All prehospital run sheets were linked to trauma registry data. The main outcome was severe trauma, defined as death within 72 hours, admission to the intensive care unit within 24 hours or an Injury Severity Score greater than 15 . We assessed sensitivity, specificity and rates of overtriage.

Results: Of 16805 patients in the study population, 1113 $(6.62 \%)$ had severe trauma. The combination of all 3 triage criteria (PHI score $\geq 4$, HVI presence and EMT judgment) performed best for identifying patients with severe trauma, with a sensitivity of $74.2 \%$ but with an overtriage rate of $85.1 \%$. Alone, EMT judgment had the highest sensitivity and a $\mathrm{PHI}$ score of 4 or greater had the lowest rate of overtriage.

Conclusion: Although the combination of PHI score, HVI presence and EMT judgment offers the highest sensitivity for the identification of patients that could benefit from direct transport to a level-I trauma centre, overall sensitivity remains low and overtriage is high. More research is required to improve prehospital triage.

Keywords: trauma, triage, prehospital, emergency medical system, emergency medical technician, ambulance, injury severity

\section{RÉSUMÉ}

Objectif : Nous avons cherché à évaluer la performance de I'indice préhospitalier (IPH) et de la détermination de la présence d'un impact à haute vélocité (IHV) ainsi que la contribution du jugement du technicien ambulancier lors du triage préhospitalier de patients traumatisés.

Méthodes : La population étudiée incluait tous les patients traumatisés en préhospitalier transportés par un service médical d'urgence à 2 centres de traumatologie de niveau I pour adultes. Toutes les données recueillies en préhospitalier ont été liées à celles du registre des traumatismes. Les principales mesures de résultats étaient un traumatisme grave, défini comme un traumatisme entraînant la mort dans les 72 heures, l'admission à l'unité de soins intensifs dans les 24 heures ou un indice de gravité de la blessure supérieur à 15. Nous avons évalué la sensibilité, la spécificité et les taux de surtriage.

Résultats : Parmi les 16805 patients de la population étudiée, $1113(6,62 \%)$ avaient subi un traumatisme grave. La combinaison des 3 critères de tri (score de I'IPH $\geq 4$, présence d'un IHV et jugement du technicien ambulancier) a donné les meilleurs résultats pour dépister les patients victimes de traumatismes graves, avec une sensibilité de $74,2 \%$, mais un taux de surtriage de $85,1 \%$. Seul, le jugement du technicien ambulancier affichait la plus haute sensibilité, et un score IPH de 4 ou plus donnait le plus faible taux de surtriage.

Conclusion : Bien que la combinaison IPH, présence d'un IHV et jugement du technicien ambulancier offre la plus grande sensibilité pour le dépistage de patients qui pourraient bénéficier du transport direct à un centre de traumatologie de niveau I, la sensibilité globale demeure faible et le surtriage élevé. II faut entreprendre d'autres recherches pour améliorer le triage préhospitalier.

\section{INTRODUCTION}

Trauma is the leading cause of death for people aged $1-45$ years in Canada ${ }^{1}$ and in the United States. ${ }^{2}$ There is strong evidence that regionalized trauma systems

From the *Unité de recherche en traumatologie-urgence-soins intensifs, Centre de recherche du CHA (Hôpital de l'Enfant-Jésus), Québec City, Que., the †Département de médecine sociale et préventive, Université Laval, Québec City, Que., the ‡Départment de médecine familliale - section médecine d'urgence, Université Laval, Québec City, Que., the §Unité de recherche en santé des populations, Centre de recherche du CHA, Québec City, Que., and the đDivision de chirurgie thoracique, Centre hospitalier universitaire de Montréal (Hôpital Notre-Dame), Montréal, Que.

Presented in part at the Canadian Association of Emergency Physicians Annual Scientific Assembly, Edmonton, Alta., May 29-Jun. 1, 2005

Submitted Mar. 9, 2009; Revised Oct. 7, 2009; Accepted Oct. 26, 2009

This article has been peer reviewed. 
reduce mortality. ${ }^{3-5}$ Fundamental to all trauma systems are the concepts of triage and transport directly from the scene of injury to definitive care. Several triage criteria have been developed based on 2 competing goals: high sensitivity to get the right patient to the right hospital at the right time, and low rates of overtriage so that trauma centres are not overburdened with less severe cases. ${ }^{6-9}$ Although there is no consensus on acceptable performance levels for trauma triage, levels of sensitivity greater than $85 \%$, a positive predictive value of greater than $50 \%$ and overtriage of less than $50 \%$ have been suggested. ${ }^{8,9}$

Several triage criteria have been developed, including the Prehospital Index (PHI) ${ }^{10}$ and the presence of highvelocity impact (HVI) based on the mechanism of injury. ${ }^{11}$ The PHI consists of 5 elements observed onscene: systolic blood pressure, heart rate, respiratory status, level of consciousness and penetrating torso injury. It increases with severity and ranges from 0 to 24. A score of 4 serves as the cut-off point for transport to a trauma centre. The PHI has been the object of several validation studies. ${ }^{12-17}$

The evaluation of HVI presence is intended to identify injuries involving a high level of energy transfer. Specific examples include a fall greater than $7 \mathrm{~m}(20 \mathrm{ft})$, another victim killed in the same accident, ejection from a motor vehicle, cabin structural intrusion and pedestrian or cyclist hit by a motor vehicle travelling faster than $8 \mathrm{~km} / \mathrm{h}(5 \mathrm{mile} / \mathrm{h})$. Bond and colleagues ${ }^{18}$ reported that combining PHI score and HVI presence led to better triage (and minimized overtriage), but lower sensitivity. Even though some mechanisms of injury appear predictive of major injury, ${ }^{19}$ not all seem as important as previously reported. ${ }^{19-21}$ Therefore, the most useful definition of HVI presence is unclear. Tamim and coauthors ${ }^{17}$ have demonstrated that age affects the performance of PHI and HVI criteria.

In addition to PHI or HVI criteria, emergency medical technician (EMT) judgment can also be used to initiate transport to a specialized centre. ${ }^{13}$ However, the use of EMT judgment has recently been put into question. ${ }^{22}$ Moreover, most triage criteria were developed at a time when mortality following severe trauma was high. Currently, mature trauma systems report in-hospital mortality as low as $8 \%$ in major trauma patients in Quebec or $1 \%$ in general trauma populations in Canada. ${ }^{23}$ This change in the profile of trauma outcomes influences the mechanisms and the goals of prehospital triage.

The primary objectives of this study were to evaluate the performance of the PHI and HVI as triage criteria, and to evaluate the contribution of EMT judgment in identifying major trauma patients in a mature trauma system with low overall mortality rates. A secondary objective was to assess the performance of triage criteria in the geriatric population, as age has been reported to be an important factor in prehospital trauma triage..$^{22,24}$

\section{METHODS}

\section{Trauma system}

Urgences-santé is a nonprofit governmental agency that manages all ambulance runs in Greater Montréal, an area of $745 \mathrm{~km}^{2}$ serving a population of 2.1 million. Of 20 hospitals, 2 were designated level-I trauma centres for adults in 1992. Patients are treated on-scene by advanced EMTs, who use prehospital trauma life support guidelines. Official triage protocols, standardized for the entire province of Quebec, stipulate that all severely injured patients, defined by a PHI score of 4 or greater, or presence of HVI, are transported directly to a designated trauma centre. An EMT can also use clinical judgment to override a low PHI score and absence of HVI, and transport any given trauma patient to a specialized centre. Although EMTs were unaware of this study, a widely publicized concurrent quality improvement program estimated compliance to this triage protocol to be $90 \% .^{4}$ The 2 trauma centres receive the most severely injured patients in the whole region as well as the minor trauma cases that occur in their immediate vicinity.

In Montréal, 2 slight modifications of the original PHI are in use. Level of consciousness is assessed using the AVPU (alert, verbal, pain, unresponsive) scale that has 4 possible responses instead of the 3 originally proposed in the PHI. ${ }^{4}$ Penetration of the head or neck is also added to the torso criteria of the PHI. As part of the clinical assessment, the EMT is asked to categorize and record all trauma patients as either "major" or "minor." No specific criteria are attached to "major trauma." The EMT's evaluation is thus based on clinical experience and perception, but it is not assessed independently of the PHI and presence of HVI. However, data show that EMTs do code "major trauma" when the PHI score is 4 or greater and HVI presence is not reported, and conversely "minor trauma" can be used when official triage criteria are met.

\section{Study design}

The Montréal prehospital system uses a computerized 
database containing clinical information recorded by the EMT on a standardized run sheet, mandatory for each patient encounter. Emergency medical technicians produce 160000 run sheets per year, which are all electronically scanned. Ticked boxes (e.g., "major trauma") are captured by scanning sheets using computer software and written vital signs are magnified on screen for manual capture by a data entry clerk. This database supplied the cohort inception criteria and the prehospital data. The 2 level-I trauma centres use a mandatory standardized trauma registry that includes data on all trauma patients who die in hospital, are admitted to the intensive care unit (ICU), are transferred from another hospital or are admitted to hospital for longer than 2 days. This second database supplied the outcome information for the study.

The provincial health insurance number unique to each resident of Quebec was used to link the 2 databases. Both the trauma registry and the prehospital database were compiled prospectively and independently from each other and from this study. Both data sets have mandatory quality surveillance programs.

Our institutional research and ethics board approved this study.

\section{Study population}

All consecutive trauma patients who were treated onscene by EMTs and directly transported to one of the 2 designated level-I trauma centres between Jan. 1, 1997, and Dec. 31, 2000, were identified. Inclusion criteria were as follows: the patient was identified on the EMT run sheet as a trauma patient ("minor" or "major"), the patient was transported directly to one of the 2 level-I trauma centres and the patient was over 15 years of age. Patients were excluded if there was no health insurance number available on the prehospital run sheet $(<3 \%)$. Presence of HVI, major trauma according to the EMT and each of the individual components of the PHI were obtained directly from the run sheets. Because it is customary for an EMT to leave boxes unticked in situations that do not apply, empty boxes were considered to represent "normal" status.

\section{Outcomes}

We used 3 primary outcomes to identify patients with severe trauma that might benefit most from treatment at a level-I trauma centre: death within the first 72 hours of arrival (including deaths in the emergency department), ICU admission within 24 hours of arrival and an Injury Severity Score (ISS) greater than 15 . Patients were classified as having severe trauma if they had experienced any of these 3 outcomes. Patients identified in the prehospital database but not in the trauma registry were assumed not to have experienced any of the 3 outcomes.

\section{Statistical analysis}

We calculated sensitivity, specificity and overtriage $(1-$ positive predictive value) for each criterion and their combinations. We repeated all multivariate analyses in the subpopulation of patients aged 65 or older to evaluate predictive accuracy of triage criteria for trauma in geriatric patients. We compared sensitivities of different triage criteria using the McNemar test for paired data, and we set statistical significance at 0.05 .

\begin{tabular}{|c|c|}
\hline Characteristic & No. (\%) of patients* \\
\hline Age $<65 \mathrm{yr}$ & $12733(75.8)$ \\
\hline Median age, yr (IQR) & $47(29-64)$ \\
\hline Male sex & $9256(55.1)$ \\
\hline Admitted to trauma registry $\dagger$ & 3290 (19.6) \\
\hline \multicolumn{2}{|l|}{ ISS for patients admitted to registry } \\
\hline $0-14$ & 2497 (75.9) \\
\hline $15-24$ & 390 (11.9) \\
\hline $25-49$ & 370 (11.3) \\
\hline $50-75$ & $33(1.0)$ \\
\hline \multicolumn{2}{|l|}{ Mechanism of injury } \\
\hline motor vehicle crash & 6439 (38.3) \\
\hline fall & 4414 (26.3) \\
\hline stabbing & $695 \quad(4.1)$ \\
\hline gunshot wound & $102 \quad(0.6)$ \\
\hline other & $1148 \quad(6.8)$ \\
\hline unknown & 4007 (23.8) \\
\hline EMT judgment = "major" & $2858(17.0)$ \\
\hline $\mathrm{PHI} \geq 4, \mathrm{HVI}=$ yes & $301 \quad(1.8)$ \\
\hline $\mathrm{PHI} \geq 4, \mathrm{HVI}=\mathrm{no}$ & 499 (3.0) \\
\hline $\mathrm{PHI}<4, \mathrm{HVI}=$ yes & 1095 (6.5) \\
\hline $\mathrm{PHI}<4, \mathrm{HVI}=\mathrm{no}$ & $963 \quad(5.7)$ \\
\hline EMT judgment = "minor" & $13947(83.0)$ \\
\hline $\mathrm{PHI} \geq 4, \mathrm{HVI}=$ yes & $41 \quad(0.2)$ \\
\hline $\mathrm{PHI} \geq 4, \mathrm{HVI}=\mathrm{no}$ & $138 \quad(0.8)$ \\
\hline $\mathrm{PHI}<4, \mathrm{HVI}=$ yes & $2173(12.9)$ \\
\hline $\mathrm{PHI}<4, \mathrm{HVI}=\mathrm{no}$ & 11595 (69.0) \\
\hline
\end{tabular}

$\mathrm{EMT}=$ emergency medical technician: $\mathrm{HVI}=$ high-velocity impact: $I \mathrm{OR}=$ interquartile range; ISS = Injury Severity Score; $\mathrm{PHI}=$ Prehospital Index.

*Unless otherwise indicated.

†Eligibility criteria for patients admitted to trauma registry were any of the following: death, admission to the intensive care unit, transfer from another hospital or hospital stay $>2$ days. 


\section{RESULTS}

A total of 16805 trauma patients were identified and included in the cohort (Table 1). Overall, 3290 (19.6\%) of these patients were present in the trauma registry. The distribution of specific triage criteria in the full cohort was as follows: there were $979(5.8 \%)$ patients with a PHI score of 4 or greater, 3610 (21.5\%) for whom HVI was present and $2858(17.0 \%)$ were judged as having major trauma by the EMT. In the subgroup of patients not identified in the trauma registry data set $(n=13515)$, there were $471(3.5 \%)$ patients with a PHI score of 4 or greater, 2812 (20.8\%) with HVI present and 1687 $(12.5 \%)$ judged as having major trauma by the EMT.

In the whole sample, 144 patients $(0.9 \%)$ died within 72 hours, 785 (4.7\%) were admitted to the ICU within
24 hours and 793 (4.7\%) had an ISS greater than 15 (Table 2). A total of $1113(6.62 \%)$ had any one of these outcomes and were therefore considered to have severe trauma, the outcome used for analysis. Severe trauma was most prevalent in patients with a PHI score of 4 or greater, followed by patients judged as having major trauma by EMT and, finally, patients with the presence of HVI.

The highest sensitivity was attained by combining all 3 triage criteria (i.e., "any one of") (Table 3). Still, in terms of sensitivity, the next best combination of 2 criteria was HVI presence and/or EMT judgment, and the best single criteria was EMT judgment. The difference in sensitivity between the combination of all 3 criteria (sensitivity $74.5 \%$ ) and HVI presence and/or EMT judgment (sensitivity $72.5 \%$ ) as well as the difference

Table 2. Outcomes of $\mathbf{1 6} \mathbf{8 0 5}$ trauma patients according to severity of injury

\begin{tabular}{l} 
Triage tool \\
\cline { 2 - 6 }
\end{tabular}

Table 3. Predictive ability of the triage criteria and their combinations to detect severe trauma*

\begin{tabular}{|c|c|c|c|c|c|}
\hline Triage criteria & Sensitivity $(95 \% \mathrm{Cl})$ & Specificity $(95 \% \mathrm{Cl})$ & PPV (95\% Cl) & NPV (95\% Cl) & $\begin{array}{c}\text { Rate of } \\
\text { overtriage, \% }\end{array}$ \\
\hline \multicolumn{6}{|l|}{$\begin{array}{l}\text { Actual situation (i.e., any of the } 3 \\
\text { criteria is present): }\end{array}$} \\
\hline $\begin{array}{l}\mathrm{PHI} \geq 4 \text { and/or HVI present and/or } \\
\text { EMT "major" }\end{array}$ & $74.2(71.5-76.7)$ & $70.0(69.3-70.7)$ & $14.9(14.0-15.9)$ & $98.2(97.9-98.4)$ & 85.1 \\
\hline \multicolumn{6}{|l|}{ If only 2 criteria were used: } \\
\hline $\mathrm{PHI} \geq 4$ and/or HVI present & $59.8(56.8-62.7)$ & $77.2(76.5-77.8)$ & $15.7(14.6-16.8)$ & $96.4(96.1-96.7)$ & 84.3 \\
\hline $\mathrm{PHI} \geq 4$ and/or EMT "major" & $66.5(63.6-69.3)$ & $85.4(84.8-85.9)$ & $24.4(22.9-25.9)$ & $97.3(97.0-97.6)$ & 75.6 \\
\hline HVI present and/or EMT "major" & $72.5(69.8-75.1)$ & $72.8(72.1-73.5)$ & $15.9(14.9-16.9)$ & $97.4(97.1-97.7)$ & 84.1 \\
\hline \multicolumn{6}{|l|}{ If only 1 criterion was used: } \\
\hline $\mathrm{PHI} \geq 4$ & $35.0(32.2-37.9)$ & $96.3(95.9-96.5)$ & $39.8(36.8-43.0)$ & $95.4(95.1-95.8)$ & 60.2 \\
\hline HVI present & $40.8(37.9-43.7)$ & 79.9 (79.3-80.5) & $12.6(11.5-13.7)$ & $95.0(94.6-95.4)$ & 87.4 \\
\hline EMT "major" & $64.7(61.7-67.4)$ & $86.4(85.8-86.9)$ & $25.2(23.6-26.8)$ & $97.2(96.9-97.4)$ & 74.8 \\
\hline
\end{tabular}


between HVI presence and/or EMT judgment and EMT judgment alone (64.7\%) was statistically significant (MacNemar $p<0.001)$. Improved sensitivity did, evidently, come at the cost of lower specificity and increased overtriage.

Sensitivity of all triage criteria was lower among patients aged 65 years or older (Table 4). Moreover, specificity was increased for all criteria and combinations, and the rate of overtriage decreased by at least $10 \%$. The combination of all 3 predictors reached the highest sensitivity (59.6\%). However, the lowest rate of overtriage $(50.0 \%)$ was achieved by the PHI alone (specificity of $98.4 \%$ ).

\section{DISCUSSION}

This study evaluated the validity of 3 widely used trauma triage criteria on a consecutive series of patients served by 2 level-I Canadian urban trauma centres. This study represents another step toward the improvement of prehospital trauma triage. The results help enhance our understanding of the relative performance of 3 triage criteria and their combinations for identifying patients with severe trauma who would benefit from direct transportation to a level-I trauma centre.

Study results suggest that a combination of the 3 triage criteria (PHI score $\geq 4$, HVI presence and EMT judgment) leads to the identification of the highest proportion of severe trauma. However, the combination of all 3 criteria still resulted in sensitivity rates below the $85 \%$ suggested to be acceptable in the literature and overtriage rates above the $50 \%$ suggested as acceptable in the literature. ${ }^{8,9}$

The present study is based on the hypothesis that sensitivity is by far the most important characteristic of a triage tool. Providing appropriate definitive care as quickly as possible in order to prevent adverse outcomes remains the priority of a trauma system. However, high rates of overtriage may compromise the overall quality of patient care. In this study, the use of any single criterion or combinations of criteria led to an overtriage rate well over the $50 \%$ level considered acceptable. ${ }^{8,9}$ The trade-off between sensitivity and overtriage is a crucial issue and tolerance to overtriage will vary among health systems. High overtriage may be considered safe in a universal health system where every patient will receive hospital care anyway and where the prehospital system uses quotas to prevent hospital overload, as is the case in the setting of this study. In such a system, if a trauma centre receives more minor trauma, it consequently receives fewer patients with other health problems. In systems without this safeguard, however, trauma centre performance may be compromised by severe overtriage. Even in a system with quotas, a high number of minor cases may monopolize trauma services such as orthopedics and scans, thus compromising the care of patients with severe trauma.

Judgment of EMTs was the best single predictor of severe trauma. Despite not being a standardized criterion, the value of EMT judgment in prehospital triage

Table 4. Predictive ability of the triage criteria and their combinations to detect severe trauma* in patients aged 60 years or older

\begin{tabular}{|c|c|c|c|c|c|}
\hline Triage criteria & Sensitivity $(95 \% \mathrm{Cl})$ & Specificity $(95 \% \mathrm{Cl})$ & PPV (95\% Cl) & NPV $(95 \% \mathrm{Cl})$ & $\begin{array}{c}\text { Rate of } \\
\text { overtriage, \% }\end{array}$ \\
\hline \multicolumn{6}{|l|}{$\begin{array}{l}\text { Actual situation (i.e., any of the } 3 \\
\text { criteria is present): }\end{array}$} \\
\hline $\begin{array}{l}\mathrm{PHI} \geq 4 \text { and/or HVI present and/or } \\
\mathrm{EMT} \text { "major" }\end{array}$ & $59.6(53.5-65.4)$ & $88.8(87.7-89.7)$ & $27.9(24.3-31.7)$ & $96.8(96.1-97.3)$ & 72.1 \\
\hline \multicolumn{6}{|l|}{ If only 2 criteria were used: } \\
\hline $\mathrm{PHI} \geq 4$ and/or HVI present & $40.4(34.6-46.5)$ & $93.1(92.2-94.1)$ & $29.9(25.3-34.8)$ & $95.5(94.2-96.2)$ & 70.1 \\
\hline $\mathrm{PHI} \geq 4$ and/or EMT "major" & $54.5(48.5-60.5)$ & $93.9(93.1-94.6)$ & $39.3(34.4-44.4)$ & $96.6(96.0-97.2)$ & 60.7 \\
\hline HVI present and/or EMT "major" & $58.5(52.4-64.4)$ & 90.9 (89.9-91.8) & $31.9(27.9-36.1)$ & $96.8(96.1-97.3)$ & 68.1 \\
\hline \multicolumn{6}{|l|}{ If only 1 criterion was used: } \\
\hline $\mathrm{PHI} \geq 4$ & $22.0(17.3-27.4)$ & $50.0(40.8-59.2)$ & 98.4 (97.9-98.8) & $79.3(78.6-80.1)$ & 50.0 \\
\hline HVI present & $28.2(22.9-33.9)$ & $27.1(22.0-32.6)$ & $94.5(93.7-95.2)$ & $94.7(94.0-95.4)$ & 72.9 \\
\hline EMT "major" & $52.7(46.7-58.7)$ & $42.1(36.8-47.5)$ & $94.7(93.9-95.4)$ & $96.5(95.8-97.1)$ & 57.9 \\
\hline
\end{tabular}


has been demonstrated by others. ${ }^{13,22,25-27}$ Emerman and colleagues $^{13}$ found EMT judgment to be equivalent to physiologic trauma triage criteria. However, this could be explained by the fact that EMT judgment is not independent of PHI and HVI criteria and probably represents a combination of both, in addition to EMT experience. Indeed, EMT judgment alone reached a sensitivity of $64.7 \%$ in the present study, just superior to that obtained by the combination of $\mathrm{PHI}$ score and presence of HVI (59.8\%). Nonetheless, among the 963 patients judged as having major trauma by the EMT while the other 2 criteria were absent, 157 had a severe trauma outcome. This suggests that some major trauma may not be identified without the clinical judgment of an EMT. The combination of HVI presence and EMT judgment achieved the highest sensitivity among combinations of any 2 criteria. The usefulness of physiologic criteria for prehospital triage has consistently been reported..$^{28-31}$ However, the addition of PHI score only led to a small (but statistically significant) increase in sensitivity and to the identification of 15 additional severe trauma cases. Although evaluation of HVI did help detect more severe trauma patients, it was the criterion with the highest rate of overtriage. Indeed, among the subgroup of 2173 patients meeting only the HVI criterion, only $82(4 \%)$ had severe trauma. There is presently no consensus on HVI definition, and predictive mechanisms vary among publications. ${ }^{18-21,28}$ A review of injury mechanisms considered to be high impact may improve the predictive accuracy of this criterion. Indeed, a more restrictive definition of HVI has been reported to lead to lower rates of overtriage. ${ }^{18}$ Previous studies have suggested that prehospital triage should include patient age. ${ }^{17,24,32}$ The lower sensitivity of triage criteria observed in the geriatric population of the present study supports the need to account for patient age in triage rules.

The predictive accuracy of triage criteria observed in this study was inferior to that reported elsewhere. In particular, rates of overtriage were higher. The inconsistency of our results with previous publications could be explained by differing study populations. Although sensitivity and specificity are not influenced by the prevalence of outcome, overtriage will increase as the prevalence of severe trauma decreases. So far, few studies have used full prehospital data sets to evaluate triage criteria. ${ }^{13,15,18,25,27,33}$ Other studies have relied either exclusively on trauma registry data ${ }^{8,11,14,16,19,34}$ or on sampling strategies that overrepresent major trauma in their cohorts. ${ }^{12,17}$ This would explain why their rates of overtriage were lower than those observed in this study as many false-positive cases are thus excluded from the cohort. Prehospital criteria are applied to all trauma patients, not only the most severe. Validation of triage criteria should therefore be based on a full prehospital population-based study, not only on patients sufficiently injured to meet the inclusion criteria of a trauma registry or a sampling scheme.

Varying definitions of overtriage in the literature may also explain inconsistencies between rates observed in the current study and others. ${ }^{11,18}$ Bond and coworkers ${ }^{18}$ used the definition of ( 1 - specificity), which assumes that one knows which patient is considered a major trauma victim. Gabbe and colleagues ${ }^{8}$ used $(1-$ positive predictive value) in their evaluation, as we did. This last definition seems more in keeping with current practice in the prehospital setting where an EMT applies a triage decision tool and when positive, transports the patient to the appropriate level of care. Finally, lower rates of sensitivity and specificity could be due to differing patient baseline characteristics. In particular, the relatively high proportion of geriatric patients and the low proportion of penetrating injuries in the study population could explain the lower predictive accuracy observed.

\section{Limitations}

There are several limitations to this study. These include the definition of severe trauma, the possibility of information bias and the external validity of results.

Currently, the literature on validation of prehospital triage criteria is plagued by at least 2 problems: lack of population representation and controversy as to which patients benefit from trauma centre attention (i.e., who exactly should be taken to a level-I trauma centre). ${ }^{35}$ Although this study partly addresses the former by using a complete prehospital database, it is hampered by the lack of an evidence-based definition of the latter. Results of this study are interpreted under the assumption that patients who die within 72 hours of arrival, are admitted to the ICU within 24 hours or have an ISS greater than 15 require treatment in a level-I trauma centre. Although the first 2 criteria seem incontestable, the latter is debatable. More work must be done to identify which patients benefit from care at a level-I trauma centre in terms of improved short- and long-term outcome.

Information bias could have been caused by the lack of distinction between absent conditions and missing data on prehospital run sheets. The standard procedure of leaving blanks on the run sheet when the patient 
status is normal prevented us from performing a more thorough assessment of data quality. However, a rigorous quality assurance program that includes a systematic revision of all major trauma interventions in the system reduces the likelihood that information bias could severely affect our conclusions. Information bias is also present in the nonstandardized use of "major trauma" by EMTs: this label has no uniform definition, it was not the object of specific training and it has not been validated. Some cases of severe trauma may also have eluded us, as only patients transported directly to the 2 level-I trauma centres were included. However, data comparing the provincial trauma registry to the global provincial hospitalization database suggest that more than $85 \%$ of patients with very severe injuries are admitted in the trauma designated hospitals. ${ }^{36}$

The results of this study may not generalize well to populations with very different patient characteristics. In particular, the study population included relatively high proportions of elderly patients and less penetrating trauma, which may have led to an underestimation of predictive accuracy. However, our cohort shared similar characteristics to those of several previous reports on this topic. ${ }^{8,19,37}$ In addition, as only patients brought to the 2 level-I trauma centres in the Montréal area were included, the study population comprised local minor trauma, local severe trauma and severe trauma transported over a longer distance. This would tend to skew the study population toward more severe trauma but to a lesser extent than studies based on trauma registry observations only. The rate of overtriage in a truly populationbased sample is therefore likely to be even higher. The study results may also not generalize well to prehospital systems where prehospital protocols may differ. In this system, at the time of this study, EMTs could use semiautomatic defibrillators and the Combitube, but no drugs or endotracheal tubes. In addition, $20 \%$ of all ambulance run sheets are trauma related and only $10 \%$ of these (i.e., $2 \%$ of all patients) are severe enough to meet the 2 official criteria (i.e., PHI score $\geq 4$ or HVI presence), which produce high rates of overtriage. Severe trauma is thus a fairly rare event in this system.

Despite these possible limitations, the use of a database providing close representation of the total prehospital population as the inception point of the cohort, the fact that the exposure and outcome data were gathered prospectively and independently from each other, the large sample size and the thoroughness of case identification in a universal access system contribute to the strength and originality of this study.

\section{CONCLUSION}

This study suggests that among the 3 triage criteria evaluated in this study, the combination of PHI score, HVI presence and EMT judgment leads to the identification of the highest proportion of patients with severe trauma. However, the sensitivity associated with these criteria for prehospital triage is still unacceptably low and rates of overtriage are too high. Triage is an eternal compromise between sensitivity and overtriage, and tolerance to overtriage will vary among health systems. However, further refinement of triage criteria is needed to improve sensitivity while reducing overtriage.

\section{Competing interests: None declared.}

Funding: Funding was provided by Fonds de la Recherche en Santé du Québec Research Grant \#015102.

\section{REFERENCES}

1. Angus DE, Cloutier E, Albert T, et al. The economic burden of unintentional injury in Canada. Toronto (ON): Smartrisk Foundation; 1998.

2. CDC injury fact book, 2006. Center for Disease Control and Prevention. Available: www.cdc.gov/Injury/publications /FactBook/Directors_Messages-2006-a.pdf (accessed 2010 Jan 22).

3. Celso B, Tepas J, Langland-Orban B, et al. A systematic review and meta-analysis comparing outcome of severely injured patients treated in trauma centers following the establishment of trauma systems. I Trauma 2006;60:371-8, discussion 378.

4. Liberman M, Mulder DS, Lavoie A, et al. Implementation of a trauma care system: evolution through evaluation. 7 Trauma 2004;56:1330-5.

5. Mann NC, Hedges JR, Sandoval R, et al. Trauma system impact on admission site: a comparison of two states. 7 Trauma 1999;46:631-7.

6. Ciesla DJ, Sava JA, Street JH III, et al. Secondary overtriage: a consequence of an immature trauma system. 7 Am Coll Surg 2008;206:131-7.

7. Cook CH, Muscarella P, Praba AC, et al. Reducing overtriage without compromising outcomes in trauma patients. Arch Surg 2001;136:752-6.

8. Gabbe BJ, Cameron PA, Wolfe R, et al. Prehospital prediction of intensive care unit stay and mortality in blunt trauma patients. J Trauma 2005;59:458-65.

9. Senkowski CK, McKenney MG. Trauma scoring systems: a review. 7 Am Coll Surg 1999;189:491-503. 
10. Koehler JJ, Baer LJ, Malafa SA, et al. Prehospital Index: a scoring system for field triage of trauma victims. Ann Emerg Med 1986;15:178-82.

11. Lowe DK, Oh GR, Neely KW, et al. Evaluation of injury mechanism as a criterion in trauma triage. Am J Surg 1986;152:6-10.

12. Bouillon B, Lefering R, Vorweg M, et al. Trauma score systems: Cologne Validation Study. J Trauma 1997;42:652-8.

13. Emerman CL, Shade B, Kubincanek J. A comparison of EMT judgment and prehospital trauma triage instruments. JTrauma 1991;31:1369-75.

14. Jones J, Newman C, Krohmer J, et al. Accuracy of the Prehospital Index in identifying major hemorrhage in trauma victims. Prehosp Disaster Med 1993;8:237-40.

15. Koehler JJ, Malafa SA, Hillesland J, et al. A multicenter validation of the prehospital index. Ann Emerg Med 1987;16:380-5.

16. Plant JR, MacLeod DB, Korbeek J. Limitations of the prehospital index in identifying patients in need of a major trauma center. Ann Emerg Med 1995;26:133-7.

17. Tamim H, Joseph L, Mulder D, et al. Field triage of trauma patients: improving on the Prehospital Index. Am 7 Emerg Med 2002;20:170-6.

18. Bond RJ, Kortbeek JB, Preshaw RM. Field trauma triage: combining mechanism of injury with the prehospital index for an improved trauma triage tool. J Trauma 1997;43:283-7.

19. Palanca S, Taylor DM, Bailey M, et al. Mechanisms of motor vehicle accidents that predict major injury. Emerg Med (Fremantle) 2003;15:423-8.

20. Boyle MJ. Is mechanism of injury alone in the prehospital setting a predictor of major trauma - a review of the literature. J Trauma Manag Outcomes 2007;1:4.

21. Boyle MJ, Smith EC, Archer F. Is mechanism of injury alone a useful predictor of major trauma? Injury 2008;39:986-92.

22. Mulholland SA, Gabbe BJ, Cameron P. Is paramedic judgement useful in prehospital trauma triage? Injury 2005;36:1298-305.

23. Canadian Institute for Health Information. National trauma registry. Ottawa (ON): The Institute; 2009. Available: http://secure.cihi.ca/cihiweb/dispPage.jsp?cw_page=services_n tr_e (accessed 2010 Jan 19).

24. Chang DC, Bass RR, Cornwell EE, et al. Undertriage of elderly trauma patients to state-designated trauma centers. Arch Surg 2008;143:776-81, discussion 782.

25. Fries GR, McCalla G, Levitt MA, et al. A prospective comparison of paramedic judgment and the trauma triage rule in the prehospital setting. Ann Emerg Med 1994;24:885-9.

26. Mulholland SA, Cameron PA, Gabbe BJ, et al. Prehospital prediction of the severity of blunt anatomic injury. 7 Trauma 2008;64:754-60.

27. Simmons E, Hedges JR, Irwin L, et al. Paramedic injury severity perception can aid trauma triage. Ann Emerg Med 1995;26:461-8.

28. Henry MC, Hollander JE, Alicandro JM, et al. Incremental benefit of individual American College of Surgeons trauma triage criteria. Acad Emerg Med 1996;3:992-1000.

29. Lehmann R, Brounts L, Lesperance K, et al. A simplified set of trauma triage criteria to safely reduce overtriage: a prospective study. Arch Surg 2009;144:853-8.

30. Lehmann RK, Arthurs ZM, Cuadrado DG, et al. Trauma team activation: simplified criteria safely reduces overtriage. Am J Surg 2007;193:630-4, discussion 634-5.

31. Luk SS, Jacobs L, Ciraulo DL, et al. Outcome assessment of physiologic and clinical predictors of survival in patients after traumatic injury with a trauma score less than 5. 7 Trauma 1999;46:122-8.

32. Henry MC. Trauma triage: New York experience. Prehosp Emerg Care 2006;10:295-302.

33. Knopp R, Yanagi A, Kallsen G, et al. Mechanism of injury and anatomic injury as criteria for prehospital trauma triage. Ann Emerg Med 1988;17:895-902.

34. Baxt WG, Berry CC, Epperson MD, et al. The failure of prehospital trauma prediction rules to classify trauma patients accurately. Ann Emerg Med 1989;18:1-8.

35. Newgard CD, Hedges JR, Diggs B, et al. Establishing the need for trauma center care: Anatomic injury or resource use? Prehosp Emerg Care 2008;12:451-8.

36. Lavoie A, Gagne M, Belcaid A, et al. Trauma registry inclusion criteria and severe injury representativeness [abstract]. J Trauma 2008;64:551.

37. Cottington EM, Young JC, Shufflebarger CM, et al. The utility of physiological status, injury site, and injury mechanism in identifying patients with major trauma. 7 Trauma 1988;28:305-11.

Correspondence to: Dr. Andre Lavoie, Centre de recherche du CHA (Hôpital de l'Enfant-Jésus), Unité de recherche en traumatologiemédecine d'urgence-soins intensifs, $140118^{\mathrm{e}}$ rue, Québec City QC G1J 1Z4; andre.lavoie.trauma.cha@ssss.gouv.qc.ca 